\title{
Multiple roles of motor imagery during action observation
}

\author{
Stefan Vogt ${ }^{1 *}$, Franck Di Rienzo ${ }^{2}$, Christian Collet ${ }^{2}$, Alan Collins ${ }^{1}$ and Aymeric Guillot ${ }^{2,3 *}$ \\ ${ }^{1}$ Department of Psychology, Lancaster University, Lancaster, UK \\ ${ }^{2}$ Centre de Recherche et d'Innovation sur le Sport, équipe Performance Motrice, Mentale et du Matériel, Université de Lyon, Université Claude Bernard Lyon 1 , \\ Villeurbanne, France \\ ${ }^{3}$ Institut Universitaire de France, Paris, France
}

Edited by:

Magdalena letswaart, University of

Stirling, UK

\section{Reviewed by:}

Magdalena letswaart, University of Stirling, UK

Arto Olavi Laihinen, Rehamed-Neuro

$\mathrm{GmbH}$, Germany

*Correspondence:

Stefan Vogt, Department of

Psychology, Fylde College,

Lancaster University, Lancaster LA1

4YF, UK

e-mail: s.vogt@lancaster.ac.uk; Aymeric Guillot, Centre de

Recherche et $d^{\prime}$ Innovation sur le Sport, Université Claude Bernard

Lyon 1, 27-29 Boulevard du 11

Novembre 1918, 69622 Villeurbanne

Cedex, France

e-mail: aymeric.guillot@univ-lyon1.fr
Over the last 20 years, the topics of action observation (AO) and motor imagery (MI) have been largely studied in isolation from each other, despite the early integrative account by Jeannerod (1994, 2001). Recent neuroimaging studies demonstrate enhanced cortical activity when $\mathrm{AO}$ and $\mathrm{MI}$ are performed concurrently ("AO+MI"), compared to either $\mathrm{AO}$ or $\mathrm{Ml}$ performed in isolation. These results indicate the potentially beneficial effects of $\mathrm{AO}+\mathrm{MI}$, and they also demonstrate that the underlying neurocognitive processes are partly shared. We separately review the evidence for $\mathrm{Ml}$ and $\mathrm{AO}$ as forms of motor simulation, and present two quantitative literature analyses that indeed indicate rather little overlap between the two bodies of research. We then propose a spectrum of concurrent $\mathrm{AO}+\mathrm{Ml}$ states, from congruent $\mathrm{AO}+\mathrm{Ml}$ where the contents of $\mathrm{AO}$ and $\mathrm{MI}$ widely overlap, over coordinative $\mathrm{AO}+\mathrm{Ml}$, where observed and imagined action are different but can be coordinated with each other, to cases of conflicting $A O+M I$. We believe that an integrative account of $\mathrm{AO}$ and $\mathrm{MI}$ is theoretically attractive, that it should generate novel experimental approaches, and that it can also stimulate a wide range of applications in sport, occupational therapy, and neurorehabilitation.

Keywords: motor simulation, mirror neurons, joint action, observational practice, mental practice, video therapy, occupational therapy, motor rehabilitation

\section{INTRODUCTION}

In this paper we contribute to the emerging integration of research on action observation $(\mathrm{AO})$ and motor imagery $(\mathrm{MI})$. We outline a coherent account of both forms of action representation, which have been typically studied in their own right and by different scientific communities and sub-communities (Moran et al., 2012). Our first point is not new: observers can engage in $\mathrm{AO}$ and MI simultaneously ("AO+MI"), and doing so does not take particular skill. Such integrated $\mathrm{AO}+\mathrm{MI}$ appears to be more pervasive than either form of action representation alone. Our second and main point is that the contents of such simultaneous $\mathrm{AO}+\mathrm{MI}$ need not coincide. We propose that there is a spectrum from fully congruent $\mathrm{AO}+\mathrm{MI}$, where the observer imagines performing the observed action, perhaps through periods of partial occlusion from sight and enriched by the imagined kinesthetic sensations that would arise during one's own motor execution, through to scenarios where the contents of $\mathrm{AO}$ and $\mathrm{MI}$ conflict, that is, where co-representation of two different actions is difficult or impossible to sustain and where markers of representational depth indicate competition. Lying between the extremes of congruent $\mathrm{AO}+\mathrm{MI}$ and incongruent, conflicting contents of $\mathrm{AO}$ and $\mathrm{MI}$ is the co-representation of two different actions that can be coordinated in some manner. For example, in combat sports, I might watch a video recording of a future opponent whilst simultaneously imagining myself performing specific technical attacks or defense movements against that opponent. We believe that this proposed spectrum from congruent over coordinative to conflicting $\mathrm{AO}+\mathrm{MI}$ states will motivate researchers to probe the two component processes, as well as their interaction, in greater depth than previously undertaken. At the same time, we can see tremendous opportunities for examining the application of various forms of concurrent $\mathrm{AO}+\mathrm{MI}$ in motor learning and neurorehabilitation.

Our article is organized as follows: In the first section, we turn to the field of motor rehabilitation, where a number of research groups have already made a research-based case for combining $\mathrm{AO}$ and MI. Both forms of action representation have been proposed as promising adjunct treatments to conventional physiotherapy, but an integrated approach to treatment is still largely absent. We review recent neuroimaging studies which underpin the proposal of integrating $\mathrm{AO}$ and $\mathrm{MI}$ in motor rehabilitation and briefly point to future opportunities and open questions. In section "Action observation and motor imagery-a continuum," we outline an integrative account of $\mathrm{AO}$ and $\mathrm{MI}$ as motor simulation, inspired by the early contribution by Shepard (1984). In section "Motor imagery as motor simulation," we review the evidence, from both behavioral and neuroimaging studies, for MI as a prototypical form of action simulation, as originally proposed by Jeannerod $(2001,2006)$. In section "Research on action observation and motor imagery," we turn to research on $\mathrm{AO}$, which has generated comparable evidence for motor simulation during $\mathrm{AO}$. We then present evidence from two quantitative literature analyses for the rather scarce overlap between research on MI and on $\mathrm{AO}$, and we discuss the links that have previously been made between the two forms of action representation. In section "Multiple roles of motor imagery during action observation," we then describe the full spectrum of $\mathrm{AO}+\mathrm{MI}$ states as outlined above, along with possible training applications. On a theoretical 
level, we propose a distinction between a default mode of action simulation during $\mathrm{AO}$ and a more specific $\mathrm{AO}+\mathrm{MI}$ state where the observer actively maps the observed action onto her/his own body schema via engaging in MI.

\section{A CASE FOR MOTOR IMAGERY DURING ACTION OBSERVATION}

In motor rehabilitation, both $\mathrm{MI}$ and $\mathrm{AO}$ have been proposed as adjunct treatments to conventional physiotherapy (e.g., Mulder, 2007; Garrison et al., 2010). The available clinical studies demonstrate varied success of both MI (e.g., Crosbie et al., 2004; Dijkerman et al., 2004; Page et al., 2007; Ietswaart et al., 2011; for review see Braun et al., 2013; Malouin et al., 2013, this issue) and AO therapy (Ertelt et al., 2007; Celnik et al., 2008; Ewan et al., 2010; Franceschini et al., 2010; Cowles et al., 2013; for review see Gatti et al., 2013), and a multi-center study on AO therapy is currently underway (Ertelt et al., 2012). Typically only one form of treatment, either $\mathrm{MI}$ or $\mathrm{AO}$, has been used as an intervention [for an exception, see Ietswaart et al. (2011)], possibly with the conclusiveness of the clinical trial in mind. However, such a "purist" approach ignores the possible benefits of a multimodal motor simulation training with $\mathrm{AO}$ and $\mathrm{MI}$ as integrated components. For example, in some of our electrophysiological and neuroimaging studies, we have deliberately combined instructions for $\mathrm{AO}$ and $\mathrm{MI}$ in the practice phases (e.g., Wehner et al., 1984; Higuchi et al., 2012), with the aim of maximizing the benefits of non-physical forms of practice, even though doing so precluded specific conclusions about the effects of pure AO vs. pure $\mathrm{MI}$ vs. combined $\mathrm{AO}+\mathrm{MI}$.

Fortunately, a number of recent neuroimaging studies have directly contrasted these conditions using healthy participants. Filimon et al. (2007) compared activations during AO, MI (visuomotor imagery without visual input), and during execution of reaching movements, and they found differences between $\mathrm{AO}$ and MI only in occipital (visual motion) regions. Furthermore, motor execution induced stronger activations than either $\mathrm{AO}$ or $\mathrm{MI}$ in a number of execution-related areas, including primary sensorimotor areas, posterior parietal cortex, and dorsal premotor cortex [see also Vogt et al. (2007), for similar results during observation, preparation, and motor execution of a complex grasping task]. In no less than four recent neuroimaging studies, passive observation was contrasted with combined $\mathrm{AO}+\mathrm{MI}$, where the instructions required participants to imagine performing the displayed movement from a first-person perspective (Macuga and Frey, 2012; Nedelko et al., 2012; Berends et al., 2013; Villiger et al., 2013). Nedelko et al. (2012) designed their conditions to match their video therapy sessions with stroke patients and included videos of simple and multiphasic hand-object interactions, as well as pantomimed actions. Combined $\mathrm{AO}+\mathrm{MI}$ induced stronger activations than passive $\mathrm{AO}$ in inferior parietal cortex, supplementary motor area (SMA), inferior frontal gyrus (IFG), caudate nucleus, and the cerebellum. Macuga and Frey (2012) contrasted passive $\mathrm{AO}, \mathrm{AO}+\mathrm{MI}$, and $\mathrm{AO}$ plus imitative execution of bimanual finger sequences. In line with the results of Filimon et al. (2007), imitative execution induced stronger activations in a number of execution-related areas. More importantly, compared to passive $\mathrm{AO}$, combined $\mathrm{AO}+\mathrm{MI}$ increased activations in the pre-SMA and left IFG, as well as cingulate cortex and anterior insula. Further, a manipulation of visual perspective of the observed action (1st- vs. 3rd-person) only produced differences in occipital regions, which the authors attributed to differential stimulation of the lower and upper visual fields in their paradigm. In the fMRI study by Villiger et al. (2013), essentially the same three conditions as in Macuga and Frey (2012) were compared for first-person displays of a kicking action. MI during $\mathrm{AO}$ resulted in enhanced activations relative to $\mathrm{AO}$ alone in bilateral ventral premotor cortex, left inferior parietal cortex, and left insula. Further, a conjunction analysis of $\mathrm{AO}+\mathrm{MI}$ and $\mathrm{AO}$ plus imitative execution showed a substantial overlap between the related activations in motor cortical areas, indicating that large parts of the motor execution network can be activated during AO+MI. Finally, Berends et al. (2013) demonstrated that the differences between combined $\mathrm{AO}+\mathrm{MI}$ and $\mathrm{AO}$ alone can also be demonstrated using EEG. The authors found substantially larger desynchronizations during $\mathrm{AO}+\mathrm{MI}$, where participants observed movie clips of repeated pincer grips.

These studies highlight two important points. First, they strengthen the evidence for a considerable overlap between $\mathrm{AO}$, $\mathrm{AO}+\mathrm{MI}$, and visually guided motor execution, in that all three forms of action representation involve a bilateral network within posterior parietal and frontal premotor cortex, also known as the "AO network" [see also meta-analysis by Caspers et al. (2010), and section "Research on action observation and motor imagery" below]. Second, $\mathrm{AO}+\mathrm{MI}$ induced stronger activations in certain regions of this network than observation alone. On this basis, all four research teams recommended the use of combined $\mathrm{AO}+\mathrm{MI}$ procedures in neurorehabilitation.

It should be noted, however, that stronger activations are not always "better," and that differential activations whilst engaging in action representation instructions do not allow direct inferences about the possible effects on skill learning. The study by Higuchi et al. (2012) illustrates this point: Participants were scanned during observational practice (involving combined $\mathrm{AO}+\mathrm{MI}$ ) and, in separate scanning sessions, during imitative execution of manual actions (guitar chords) that had previously been practiced either via AO combined with MI, or via physical practice. As expected, when scanned during $\mathrm{AO}$, a common network involving posterior parietal and premotor regions was found activated, with only minor differences between the two forms of practice (see also Cross et al., 2009). During imitative execution, the results were strikingly different: Chords that had been observationally practiced induced substantially stronger activations during imitative execution than the physically practiced chords. Given that the behavioral data indicated smaller practice effects for the observationally practiced actions than for the physically practiced actions, and given the general trend for the cortical activations to reduce with increasing practice ("neural efficiency," Kelly and Garavan, 2005; Babiloni et al., 2009, 2010), these results indicated a lack of execution-related resources in observationally practiced actions. Importantly, however, when compared with non-practiced actions the observationally practiced actions also exhibited neural efficiency effects. Thus, whilst the study by Higuchi et al. (2012) reminds us that we cannot normally expect non-physical forms of practice to produce the 
same results as physical practice, it also indicates that $\mathrm{AO}+\mathrm{MI}$ procedures can have substantial benefits. In future, it would be desirable that imaging studies contrast the practice effects of different forms of action representation, such as pure $\mathrm{AO}$, pure $\mathrm{MI}$, and $\mathrm{AO}+\mathrm{MI}$.

Taken together, the studies reviewed in this section not only illustrate the feasibility of simultaneous $\mathrm{AO}+\mathrm{MI}$ instructions, they also demonstrate the immediate facilitatory effects of combining AO with $\mathrm{MI}$, as well as longer-term positive effects on motor learning (sensu neural efficiency). Whilst further clinical trials are needed to confirm these effects in neurorehabilitation (Ertelt et al., 2012), the above studies clearly indicate that AO and MI training should not be seen as mutually exclusive means of treatment, but that their combined and simultaneous usage can be highly recommended. This conclusion will hopefully empower physiotherapists to develop and apply a wide range of tasks to help patients to (re-)engage in motor simulation processes. Many open questions remain at present, such as the suitability of specific subforms of motor simulation training for particular patient groups, the most suitable design of video therapy materials, and which perspective and modality instructions might be most appropriate.

\section{ACTION OBSERVATION AND MOTOR IMAGERY—A CONTINUUM}

Roger Shepard once caricatured "perception as externally guided hallucination, and dreaming and hallucination as internally simulated perception" (Shepard, 1984, p. 436). Similarly, we see AO as externally guided motor simulation, and MI as internally simulated execution. The idea that motor simulation might underlie both AO and MI was originally proposed by Jeannerod (1994, 2001, 2006), and more recently motor simulation, along with prediction as its most prominent cognitive function, has become a commonly accepted framework for a wide range of cognitive domains (Grush, 2004; Kilner et al., 2007; Bubic et al., 2010; Pezzulo et al., 2013). Before we turn to motor simulation in AO and $\mathrm{MI}$ in greater detail, we wish to illustrate the possible relationships between them by means of Figure 1, which is adapted from Shepard (1984) but reframed for the present purposes. Both schemata aim to distinguish different "externally and internally instigated representational processes” (ibid., p. 435).

\section{ACTION OBSERVATION}

With reference to Figure 1, the most frequently studied case of $\mathrm{AO}$ is (b), which represents observation of another person's action under favorable viewing conditions. The schema firstly suggests that this proceeds (rapidly) from sensory processing of the observed action to motor simulation processes (e.g., Eskenazi et al., 2009; Zentgraf et al., 2011; for discussion, see Kilner, 2011). Second, the orientation of the triangles indicates the externally driven character of sensory and motor processes in this case. This implies that motor simulation processes are not only initiated by sensory events but that they can also unfold in close coupling to external, temporally extended events such as observed actions. Rectangle (a) in Figure 1 indicates that motor simulation processes are not mandatory in AO. For instance, in the domain of speech perception, Scott et al. (2009) concluded that motor simulation processes are more heavily involved under impoverished

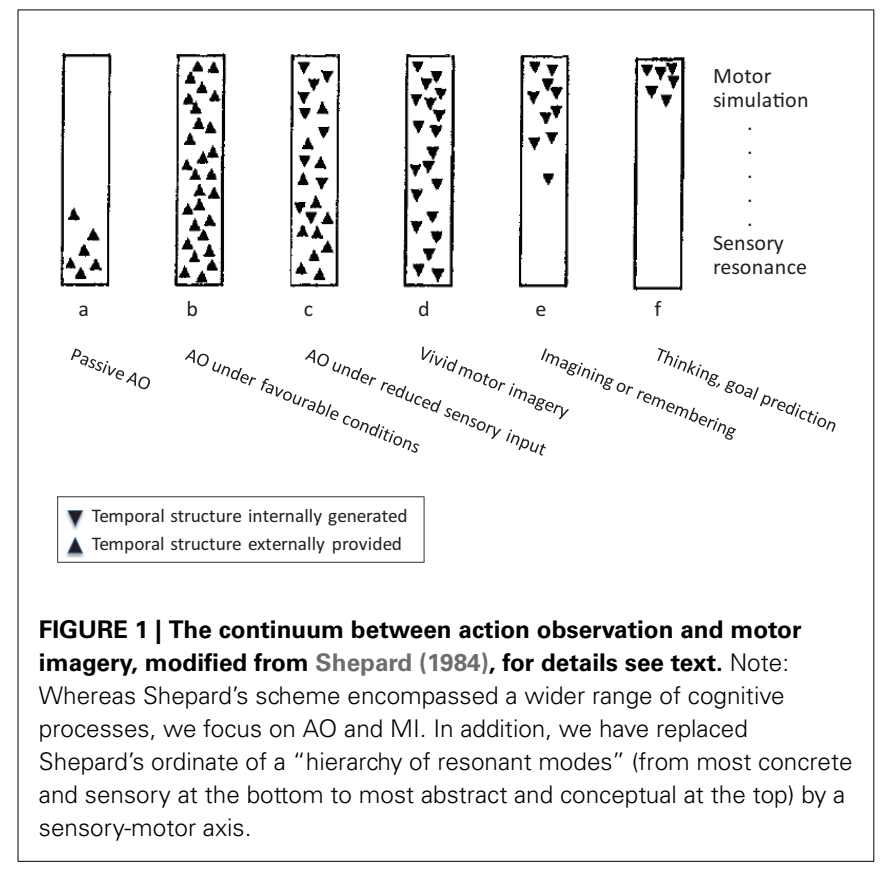

stimulation (e.g., distorted speech) so that (a) would represent the normal case in this domain. Whereas motor involvement in $\mathrm{AO}$ is a more typical finding than in speech perception, the latter at least illustrates the possibility of $\mathrm{AO}$ without the involvement of simulation processes. For instance, drawing on the study by Buccino et al. (2004), Rizzolatti and Sinigaglia (2010) conclude that "these data indicate that the recognition of the motor behavior of others can rely on the mere processing of its visual aspects" (ibid., p. 270; see also Gallese et al., 2011). Finally, rectangle (c) indicates that motor simulation during $\mathrm{AO}$ does not rely on continuous concurrent sensory guidance but can also proceed under reduced visual input, such as transient occlusion.

\section{MOTOR IMAGERY 1}

Rectangles (d) to (f) represent wholly internally driven motor simulation. We propose that vivid MI can invoke the full spectrum of sensory and motor representation $(\mathrm{d})$, whereas less vivid instances of MI, remembering, and goal prediction (e, f) might lack specific sensory features but still originate in motor simulation. In line with this, MI is commonly defined as the mental simulation of one's own performance without any associated overt movement (Jeannerod, 1994). It involves a subset of the neurocognitive preparatory and "real-time" processes of motor

\footnotetext{
${ }^{1}$ Note that in Figure 1, unlike in Shepard's (1984) original schematic, we have deliberately conflated the transition from perception $(\mathrm{a}-\mathrm{c})$ to imagery (d-f) with a change of the observer's viewpoint: for perception, we assume observation of a third person's action (the most typical situation in which mirror neurons have been studied), and for imagery, we assume MI of one's own action (first-person perspective). Already Jeannerod (1994) pointed to an intermediate simulation state, namely dynamic visual imagery of a third person's action, which comes closest to visual perception of another person's action. For simplicity of exposition we will largely neglect this case of external visual imagery in the present paper. However, we will consider perspective manipulations in AO in section "Perspective matters."
} 
execution. More specifically, the preparatory phase of both motor execution and MI (Vogt, 1994) typically includes the anticipation of distal and proximal action effects (e.g., Ziessler et al., 2012) along with, for example, an action-oriented processing of object properties (Milner and Goodale, 2008). The real-time processes during both execution and MI further involve a "sense of effort" (James, 1890), agency (Frith, 2010, 2013), the experienced or simulated kinesthetic and other sensory input, and related monitoring operations (Shallice, 2004). One main difference between actual and imagined movement is that during the latter, motor commands are inhibited throughout the motor system to prevent overt execution (Guillot et al., 2012a). Practically, inhibition during MI may be a functional process resulting from the specific contribution of neural sites usually dedicated to overt motor processing. From a multifactorial viewpoint, motor inhibition might involve both cerebral and spinal mechanisms, and three possible routes for motor command inhibition during MI have been proposed in the literature (Guillot et al., 2012a).

In summary, Figure 1 introduces the notion that $\mathrm{AO}$ and $\mathrm{MI}$ can involve a similar range of sensory and motor representational processes that constitute a continuous descriptive framework, where the two principal dimensions are the external vs. internal origin, and the emphasis on sensory resonance vs. motor simulation. $\mathrm{AO}$ and $\mathrm{MI}$ differ in that $\mathrm{AO}$ can involve motor simulation to varying degrees, and that it can rely on both external and (in part) internal guidance, whereas MI proceeds by definition in the absence of external guidance, and it can vary in the concreteness of sensory representation. These proposals will be elaborated in the next two sections.

\section{MOTOR IMAGERY AS MOTOR SIMULATION}

The ability to imagine is one of the most remarkable capacities of the mind to simulate sensations, actions and other types of experience. Morris et al. (2005, p.19) defined imagery as "the creation or re-creation of an experience generated from memorial information involving quasi-sensorial, quasi-perceptual and quasiaffective characteristics, that is under the volitional control of the imagery, and which may occur in the absence of the real stimulus antecedents normally associated with the actual experience." Within this general definition, the process of imagining motor execution is known as MI. MI is a multimodal construct based on distinct sensory modalities, and there is compelling evidence that different imagery modalities and imagery types can be performed, with visual and kinesthetic imagery being probably the most frequently reported. Diary imagery studies have shown that about two thirds of our mental images are visual in nature (Moran, 2002). During internal visual imagery (first-person perspective), people visualize the action as it would happen in real-life and see images as if through their own eyes. During external visual imagery (thirdperson perspective), people imagine, like spectators, the action that somebody is performing, regardless of the agency of that movement (i.e., whether they "see" themselves or others performing it). By contrast, kinesthetic imagery involves the sensations of how it feels to perform an action, including the force and effort perceived during movement, hence suggesting the body as a generator of forces (Jeannerod, 1994). Practically, these definitions suggest that $\mathrm{MI}$ is the prototypical form of motor simulation
(Jeannerod, 2001, 2006). While one can consider that pure visual imagery-i.e., without engaging in motor simulation - is possible (e.g., think about consequences of different actions abstractly), MI requires a motor strategy in almost all situations. In his motor simulation theory, Jeannerod (2006, p. 130) postulated that represented actions might involve a large subset of the mechanisms that usually participate in the various stages of action generation, including motor execution.

A significant number of experimental and neuroimaging studies support the proposal that MI involves motor simulation. First evidence comes from mental chronometry work, where researchers compared the time taken to imagine a movement with that needed to actually perform it (for review, see Guillot et al., 2012b). Since the pioneering contribution on this topic by Decety et al. (1989), a handful of experimental studies have shown that participants take the same time to achieve both physical and mental tasks. This is known as the principle of temporal congruence, which is based on motor prediction of the temporal features of the movement to be imagined. While there are several influencing factors likely to affect imagery times (Guillot and Collet, 2005), mental chronometry data strongly support that participants engage in motor simulation of the actual movement during MI by predicting as accurately as possible the temporal features of the corresponding action. A second line of evidence derives from recording the autonomic nervous system activity during MI. In their recent review, Collet et al. (2013) conclude that engaging in MI requires motor planning and programming operations, and anticipating the possible consequences of an action, such brain operations being accompanied by a set of physiological responses which can be recorded at the level of peripheral effectors. There is now ample evidence that MI and physical practice of the same movement elicit similar autonomic nervous system responses (e.g., Decety et al., 1991; Wuyam et al., 1995; Roure et al., 1999), and that imagery ability and efficacy can even be objectified and evaluated through autonomic responses (Collet et al., 2011).

Neuroimaging experiments also support the contention that MI involves motor simulation. Understanding the neural correlates of goal-directed action, whether executed or imagined, and exploring the neural underpinnings of different kinds of MI, has been an important purpose of cognitive brain research for the last three decades (for reviews, see Jeannerod, 1994; Grèzes and Decety, 2001; Nyberg et al., 2006; Munzert et al., 2009; Hétu et al., 2013). Briefly, studies have demonstrated that MI engages motor systems, and that the cerebral plasticity resulting from actual practice also occurred as a result of MI. These findings help to explain why MI can improve actual performance, and further contribute to motor memory consolidation. Of specific interest is the strong overlap between the neural networks mediating MI and the corresponding substrates activated during physical practice. Interestingly, Ehrsson et al. (2003) found that MI of hand, foot and tongue movements specifically activated the corresponding hand, foot and tongue sections of the primary motor cortex, hence suggesting specific motor simulation processes during MI. A similar conclusion can be drawn from studies comparing the neural networks activated during visual and kinesthetic imagery (Solodkin et al., 2004; Guillot et al., 2009), as motor systems were 
found to be more active during kinesthetic imagery, which is closer to actual practice and requires considering the body as a generator of forces to simulate the movement. Finally, a seminal clinical study in a patient with bilateral parietal lesions showed a complete unawareness of movement execution during imagery, where the patient exhibited hand movements during MI of the same body segments while explicitly denying that they occurred (Schwoebel et al., 2002). In other words, this patient engaged in complete motor simulation but failed to inhibit the motor consequences of MI which usually preclude actual movement.

A last line of (indirect) evidence of motor simulation during MI comes from experimental studies showing practice and instantaneous priming effects. Many studies of mental practice effects have demonstrated the efficacy of MI for improving motor performance and consolidation (for reviews, see Feltz and Landers, 1983; Driskell et al., 1994; Weinberg, 2008; Schuster et al., 2011). Such simulation of movements may engage relevant motor-related areas and might further build associations among processes implemented in different areas, hence facilitating subsequent motor execution (Jeannerod, 2001; Kosslyn, 2010). Recently, Ramsey et al. (2010) further demonstrated that imagining an action that was different to the to-be-performed action interfered with action execution. This finding shows that MI is likely to prime the motor system to produce the action, hence supporting that MI involves motor simulation processes (see also Vogt, 1995, 1996).

\section{RESEARCH ON ACTION OBSERVATION AND MOTOR IMAGERY}

While the general topic of mental imagery, if not MI itself, is one of the oldest areas of inquiry in psychology (Galton, 1883; James, 1890; Sully, 1892; Titchener, 1909), by contrast, "action observation" as a phrase seems not to have become prominent in the psychological literature until the 1990s, following a series of much-cited papers on mirror neurons and their properties (Di Pellegrino et al., 1992; Gallese et al., 1996; Rizzolatti et al., 1996, see Rizzolatti and Fabbri-Destro, 2010). Of course, this is not to say that observation of action was ignored by psychological research prior to this: it clearly was not. However, AO was given a new, or renewed, significance by the discovery of mirror neurons and developments in the understanding of perception-action links. Whereas the computational stages in MI, from the intention to act to real-time imagery, are most likely highly similar to those in non-imagined actions, the notion of direct links between $\mathrm{AO}$ and the motor system is less intuitive, and only over the last two decades, theorizing in neuroscience and psychology has fully embraced the latter idea. We now briefly recapitulate these developments, with a view on the commonalities and differences between $\mathrm{AO}$ and $\mathrm{MI}$.

The discovery of mirror neurons in the macaque monkey was made in the context of motor neuroscience (Rizzolatti and FabbriDestro, 2010). The original findings opened up the possibility of establishing action understanding as a new, cognitive function of the motor system, and this pursuit has been a strong driver of the related research from its very beginning (Rizzolatti and Sinigaglia, 2010). Furthermore, once the existence of mirror neurons was established, for experimental scientists in various disciplines the study of $\mathrm{AO}$ and related imitative phenomena promised to illuminate intuitively appealing psychological topics such as empathy and theory of mind (but see Frith and Frith, 2006, 2012; Van Overwalle and Baetens, 2009). This prompted an impressive research effort into potentially similar mirror mechanisms in the human brain (Rizzolatti and Sinigaglia, 2010). Whereas the number of human brain regions with mirror properties and their exact functions is still under debate (e.g., Rizzolatti, 2005; Gallese et al., 2011), a large number of neuroimaging studies have demonstrated that motor cortical structures in the ventral and dorsal premotor cortex and in the adjacent caudal sector of the IFG are typically activated during AO, together with visual temporal and posterior parietal regions (Caspers et al., 2010), as well as somatosensory cortex (Keysers et al., 2010). Together these regions are also known as the "AO network."

As we have already noted in section "A case for motor imagery during action observation," a fairly large overlap of activations was found in the few studies that have directly compared $\mathrm{AO}$ and $\mathrm{MI}$, possibly indicating that basic motor simulation processes are shared between MI and AO. Kilner (2011) recently proposed a two-process account of AO, where the initial action recognition (via a ventral temporo-frontal pathway) is segregated from motor simulation (via the parieto-frontal mirror circuit). This proposal does not preclude the rapid and simultaneous operation of the two processes, and it helps to clarify our present focus on the second process in Kilner's framework, motor simulation (Pezzulo et al., 2013). Motor simulation, in the sense of an internal, online representation of the observed action, is particularly useful when the observer needs to predict a certain temporal landmark (e.g., object release) of the observed action for purposes such as attuning one's own action toward this landmark or synchronizing one's own action with the observed action. A particularly impressive demonstration of the close coupling between observed actions and the observer's motor system was provided by Borroni et al. (2005), who showed that the excitability of the motor system exhibited a cyclical time course that closely matched that of an observed rhythmical action. In fact, such motor simulation, or "motor resonance" (Rizzolatti et al., 2002) is so universally useful that it might be described as a default mode of visuo-motor processing during AO. Finally, Schubotz (2007) and Bubic et al. (2010) have generalized this form of action prediction beyond actions that are in the behavioral repertoire of the observer and demonstrated that the premotor cortex is also involved in the prediction of non-biological events and event sequences. In summary, the available neuroimaging studies clearly support the notion of motor simulation as a default mode of $\mathrm{AO}$, which can subserve a variety of functions.

In psychological research, the seminal reaction time studies by Brass et al. (2000) and Stürmer et al. (2000), both conducted in W. Prinz' perception-action group at the Max-Planck Institute for Psychological Research, motivated a large set of studies on visuomotor priming or "automatic imitation" (for reviews, see Vogt and Thomaschke, 2007; Heyes, 2011). Basically, these studies show that observed actions can bias the speed and accuracy in which similar actions are performed, and they thus provide behavioral evidence for direct links between $\mathrm{AO}$ and motor planning. A central feature of these studies is that the observed 
actions are normally irrelevant for the observer's own action planning, which strengthens the notion of low-level, automatic perception-action links. A second feature of this line of research was its focus on static depictions of actions [e.g., the prototypical lifted index finger of Brass et al. (2000)], although more recently automatic imitation effects have also been documented for temporally extended actions, such as everyday rhythmical actions (Eaves et al., 2012).

As already pointed out in section "Action observation and motor imagery-a continuum," a key difference between AO and $\mathrm{MI}$ is their external vs. internal origin. AO involves the sensory processing and attunement to the partly unpredictable action "out there," whereas these processes are by definition not part of MI. AO thus includes a wider range of neurocognitive processes than MI, particularly action recognition and intention understanding (Rizzolatti and Sinigaglia, 2010), action prediction (Springer et al., 2013), and collaborative action (either imitative or complementary, joint action, Bekkering et al., 2009). In the present paper, we focus on an instance of $\mathrm{AO}$ which exhibits the greatest similarity to MI, namely the repeated observation of largely predictable action displays, such as the repeated observation of object grasping as used in motor rehabilitation (Ertelt et al., 2007; Nedelko et al., 2012). As described above, a large number of both neuroimaging and behavioral studies confirm the involvement of motor processes in this form of AO. Notwithstanding the considerable overlap between $\mathrm{AO}$ and $\mathrm{MI}$ in this respect, $\mathrm{AO}$ surely encompasses additional neurocognitive processes.

This brief review of neuroimaging and behavioral research on $\mathrm{AO}$ reinforces the idea that, until now, the two bodies of research have not been particularly interested in the possible commonalities between AO and MI. Both neuroscientists and psychologists were (understandably) attracted by the opportunity to manipulate visual displays, rather than MI instructions, and to demonstrate visuomotor priming effects independently of the observer's task instructions. Likewise, researchers working on MI have rarely explored the virtues of using task-irrelevant displays, given that participants can be directly instructed to engage in MI tasks. That is, as already noted in the Introduction, until now the processes of $\mathrm{AO}$ and $\mathrm{MI}$ have, with a few notable exceptions, been considered separately and investigated by different groups of scientists ${ }^{2}$ (for different sub-communities within research on MI, see Moran et al., 2012). In the remainder of this section, we present two quantitative literature analyses which tentatively support this claim, and then turn to previous points of contact and attempts of integration between the two research fields.

\section{HIGHLIGHTS OF THE AO / MI LITERATURE}

One way to demonstrate a lack of overlap between research on AO and $\mathrm{MI}$ is to revisit the related meta-analyses. Interestingly, the first such meta-analysis (Grèzes and Decety, 2001) encompassed

\footnotetext{
${ }^{2}$ There are substantial critiques of the idea of scientific communities and of citation analyses as sufficient basis for establishing them (Woolgar, 1976; Edge, 1979; Knorr-Cetina, 1982; Zuckerman, 1987). Our aim is not to make a bold claim for the existence of separate (a problematic term) communities (another problematic term) but more modestly to highlight how the theories and findings have not been cross-referenced in a way we see as productive.
}

motor execution and $\mathrm{MI}$, as well as AO. The more recent metaanalyses, however, are either focused on AO (Caspers et al., 2010, on AO and imitation; Van Overwalle and Baetens, 2009; Grosbras et al., 2012, on AO and metalizing) or on MI (Hétu et al., 2012, 2013), but not on both. Despite the wholly legitimate, narrower focus of these recent meta-analyses, overlap between the underlying individual studies would still be conceivable. However, a comparison between Caspers et al.'s (2010) and Hétu et al.'s (2013) meta-analyses shows surprisingly little overlap: Of the 87 studies on cortical activations during $\mathrm{AO}$ and imitation that were included in the meta-analysis by Caspers et al. (2010), just four are also cited in Hétu et al.'s (2013) meta-analysis on the neural correlates of MI. Even allowing for different papers being reviewed in order to justify a novel contribution, this number is small. And of the 335 papers cited by the two articles together, just 18 are cited by both. This offers at least a prima facie case for claiming that the two research areas have not overlapped to the extent one might have expected.

Looking more widely at the impressive literature dealing with these two research areas confirms that $\mathrm{MI}$ and $\mathrm{AO}$ have been largely studied in relative isolation from each other. For instance, over the last 20 years, both $\mathrm{MI}$ and $\mathrm{AO}$ have been shown to contribute to improve motor performance and facilitate motor recovery, but few researchers have investigated whether $\mathrm{MI}$ and AO might be combined or considered in a common framework. We performed a literature search from the PubMed database by selecting indexed articles related to (i) motor/movement/action imagery and (ii) motor/movement/AO and action imitation. A large sample of 2172 references (including review papers) met the topical inclusion criteria (note that a substantial number of sportrelated references do not appear in the Pubmed database and were therefore not considered in this illustrative overview of $M I$ and $A O$ research areas. This may explain the unexpectedly small number of MI studies in Sport psychology). 1203 articles investigated MI while 969 focused on AO. Each reference was then categorized as a study on either brain computer interface (BCI), cognitive psychology, rehabilitation, or sport psychology (Figure 2). The lack of $\mathrm{AO}$ research in BCI is basically expected and trivial. A larger number of AO studies than of MI studies was found in cognitive psychology, while the reverse was true in rehabilitation, which makes sense. The higher number of AO studies in sport psychology is more surprising, but the list of references retrieved from our chosen database is not exhaustive in this specific area.

The most important outcome of this analysis is that only 68 articles (3.1\% of the sample) considered both $\mathrm{AO}$ and $\mathrm{MI}$ concurrently (including 14 review papers-2 in Cognitive psychology, 2 in Sport psychology and 10 in Rehabilitation). The most famous integrated accounts of AO and MI can be found in seminal theoretical papers (Shepard, 1984; Jeannerod, 1994, 2001, 2006; Annett, 1996). These authors specifically considered both the prescriptive nature and the neural models of action representations. Holmes and Calmels $(2008,2011)$ later contrasted the definitions and benefits of $\mathrm{AO}$ and MI. However, none of these important contributions was really designed to consider the possible role of $\mathrm{MI}$ during $\mathrm{AO}$, either when $\mathrm{AO}$ and $\mathrm{MI}$ are congruent or incongruent. Few neuroimaging studies have considered both $\mathrm{AO}$ and $\mathrm{MI}$, and the neural underpinnings of $\mathrm{AO}$ and $\mathrm{MI}$ were largely studied in isolation until more 
recently, when more detailed overviews of the substrates of action simulation have been provided (Munzert et al., 2009; Lorey et al., 2013a,b). Only a handful of researchers even considered concurrent AO+MI (see section "A case for motor imagery during action observation"). The advent of transcranial magnetic stimulation and the study of corticospinal excitability increased the number of studies contrasting and/or combining $\mathrm{AO}$ and MI (Clark et al., 2004; Leonard and Tremblay, 2007; Tremblay et al., 2008; Conson et al., 2009; Liepert and Neveling, 2009; Sakamoto et al., 2009; Battaglia et al., 2011; Feurra et al., 2011; Loporto et al., 2011; Bianco et al., 2012; Tsukazaki et al., 2012). Furthermore, researchers investigating BCI systems now consider the impact of both $\mathrm{AO}$ and $\mathrm{MI}$ on the modulation of brain rhythms (e.g., Neuper et al., 2009). Finally, some experimental studies in the field of sport psychology (Lejeune et al., 1994), cognitive psychology (Vogt, 1996; Conson et al., 2009; Ramsey et al., 2010; McCormick et al., 2012; Williams et al., 2012), as well as review studies in the field of motor rehabilitation (Mulder, 2007; Johansson, 2012) have investigated the respective effects of $\mathrm{MI}$ and $\mathrm{AO}$ and whether $\mathrm{AO}$ primes or improves $\mathrm{MI}$ [for a review on learning effects, see also Gatti et al. (2013)].

Basically, most of the studies mentioned above contrasted $\mathrm{AO}$ and $\mathrm{MI}$, only very few considered concurrent $\mathrm{AO}+\mathrm{MI}$, and until recently, none had considered coordinative or conflicting $\mathrm{AO}+\mathrm{MI}$ (see below). Curiously, several researchers opposed AO and $\mathrm{MI}$ in order to find which technique is likely to be optimal in enhancing performance. For instance, Holmes and Calmels $(2008,2011)$ stated that observation can provide some solutions to the problems identified in the use of imagery (e.g., image generation and maintenance, behavioral agency, control of visual perspective, and viewing angle) and offers a more ecologically valid environment for addressing many sporting tasks. Whilst this is probably sound in some circumstances and their examples are well-illustrated, it is unclear whether or not observation as conceptualized by Holmes and Calmels is accompanied by the mental representation of the corresponding action sensu MI. Another example comes from instructions delivered in some MI experiments where researchers have drawn conclusions about MI use when the participants were actually asked to engage in combined AO and MI (Macuga and Frey, 2012). All combinations

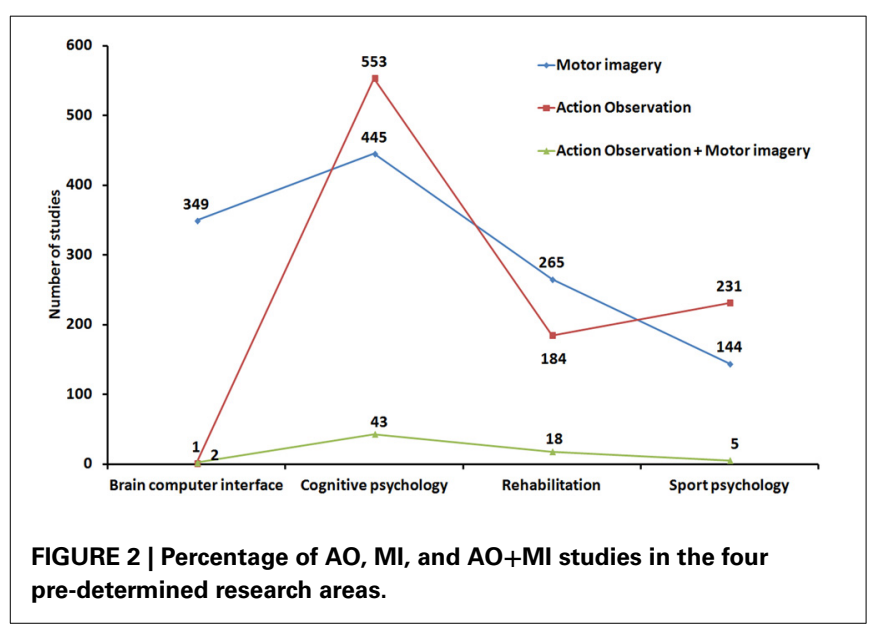

of $\mathrm{AO}+\mathrm{MI}$ procedures will now be detailed in section "Multiple roles of motor imagery during action observation," in order to provide a better overview of the possible associations and differences between $\mathrm{AO}$ and MI.

\section{MULTIPLE ROLES OF MOTOR IMAGERY DURING ACTION OBSERVATION}

In the previous section, we have pointed out that research on $\mathrm{AO}$ and $\mathrm{MI}$ has been carried out, to a large extent, by different research groups, despite the fact that integrative accounts of $\mathrm{AO}$ and $\mathrm{MI}$ as sub-forms of action representation, or action simulation, have been available for quite some time (Shepard, 1984; Jeannerod, 1994, 2001, 2006). The possibility of concurrent $\mathrm{AO}+\mathrm{MI}$ states, however, was not featured in the above accounts. In section "A case for motor imagery during action observation" we have already made a case for concurrent $\mathrm{AO}+\mathrm{MI}$, based on the recent neuroimaging studies by Macuga and Frey (2012), Nedelko et al. (2012), and Berends et al. (2013). We now explore the full spectrum of $\mathrm{AO}+\mathrm{MI}$ states (Figure 3), and begin with perhaps the most practically relevant scenario: the case of congruent $\mathrm{AO}+\mathrm{MI}$, which was also studied by the above authors.

\section{CONGRUENT AO+MI}

Here the observer is imagining self-execution whilst observing another person performing the same type of action. In a first approximation, the combined rectangles (b) and (d) in Figure 1 correspond to this scenario, where rectangle (b) represents the simulation of the observed person's action, and rectangle (d) the simulation of one's own action. In line with our definition of MI, the latter simulation includes a "sense of effort" (James, 1890), a sense of agency, and the imagined kinesthetic sensations that would arise during one's own motor execution.

At first sight, the idea of two simulation processes that run in parallel might appear unparsimonious, but consideration of incongruent and conflicting $\mathrm{AO}+\mathrm{MI}$ states (see below) will strengthen this "dual-simulation" view. Subjectively, the contrast between $\mathrm{AO}$ and $\mathrm{AO}+\mathrm{MI}$ is striking: Whereas in typical $\mathrm{AO}$, the observer can certainly engage with the observed action and, e.g., anticipate the next steps in a high jump or in a household routine, in concurrent $\mathrm{AO}+\mathrm{MI}$ one's own body schema gets "switched on" and, e.g., an observed hand movement is mapped onto one's own felt hand (and in body-oriented actions such as brushing teeth, this simulation could further include imagery of the pressure of the toothbrush on the teeth). This subjective difference is presumably reflected in the stronger activations for $\mathrm{AO}+\mathrm{MI}$ in a number of cortical sites found in the studies by Macuga and Frey (2012) and Nedelko et al. (2012). Further careful manipulation of imagery instructions during $\mathrm{AO}$ will be required to pinpoint the neural signatures of the two concurrent processes. For example, we would expect that activations in somatosensory cortex, which are consistently found during execution and AO (Keysers et al., 2010) would be substantially enhanced by related AO+MI instructions. Surprisingly, while this region has been found to be activated during MI (e.g., Porro et al., 1996; Lotze et al., 1999; Gerardin et al., 2000), the somatosensory cortex has rarely been considered a region of interest in MI studies, and, therefore, its involvement was not extensively discussed. 


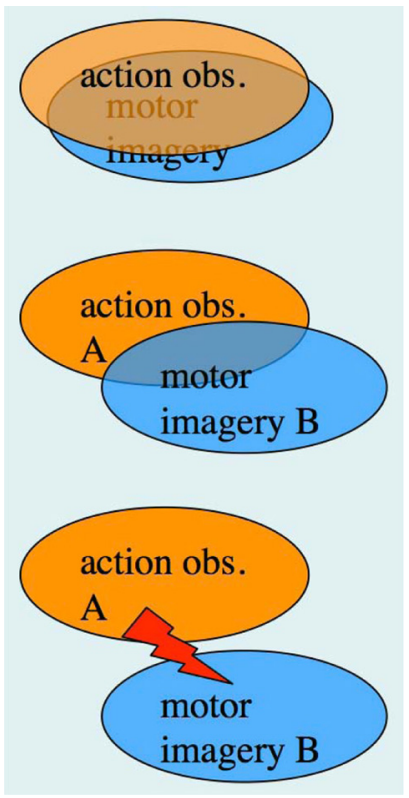

FIGURE 3 | The spectrum of concurrent AO+MI states. Top panel: congruent $\mathrm{AO}+\mathrm{Ml}$; Center panel: coordinative $\mathrm{AO}+\mathrm{MI}$, where two different actions $A$ and $B$ are co-represented in some form; Bottom panel: conflicting $\mathrm{AO}+\mathrm{MI}$ (see text for details).

The above conceptualization of $\mathrm{AO}+\mathrm{MI}$ poses a number of important questions. First, it is unclear at present to what extent participants might carry out standard $\mathrm{AO}$ instructions as $\mathrm{AO}+\mathrm{MI}$ tasks. That is, to what extent do they spontaneously imagine themselves performing the observed action, whether asked to do so or not. For example, in the prominent study by Calvo-Merino et al. (2005), observers were asked to judge "how tiring" the observed dancing movements felt,-an instruction that might well invite concurrent $\mathrm{AO}+\mathrm{MI}$. Accordingly, the frequency of spontaneous concurrent $\mathrm{AO}+\mathrm{MI}$ is an important and largely ignored confound in the majority of existing neuroimaging studies on AO. The elegant fMRI study by Oosterhof et al. (2012) underlines this possibility via an in-depth comparison of activations for $\mathrm{AO}$ during motor execution with those for $\mathrm{AO}+\mathrm{MI}$.

Second, in our overview of different simulation states in section "Action observation and motor imagery-a continuum," we have left it open as to when the observer might hold a sense of agency. Generally we would assume agency for all forms of $\mathrm{MI}$, including AO+MI. However, it is debatable whether the involvement of motor simulation processes during $\mathrm{AO}$ per se necessarily implies the sense of agency that is so typical of MI. As pointed out above, Schubotz (2007; see also Bubic et al., 2010) has argued that predictive operations of the motor system are not limited to human actions but include a variety of inanimate events. To give a recent example, Press et al. (2012) provided evidence for responses of the ventral premotor cortex, a classical "mirror" area, in coding geometric shapes. Thus, there are certainly examples of motor cortical involvement without experienced agency. Also for observation of human action, it is conceivable that motor simulation can occur without a sense of agency and without a mapping of the observed action onto the observer's own body schema. One possibility is that the observer only holds a sense of agency when he or she co-represents the observed action as their own action via MI. If this view can be substantiated, then the notion of "understanding actions from the inside" (e.g., Rizzolatti and Sinigaglia, 2010; Gallese et al., 2011) would appear to unnecessarily conflate "default mode" motor simulation processes during $\mathrm{AO}$ and the sense of agency that is experienced during $\mathrm{MI}$ and $\mathrm{AO}+\mathrm{MI}$. In other words, we suggest that the former processes do not imply agency, and that agency typically results from co-representation sensu $\mathrm{AO}+\mathrm{MI}$. The subjective experience of $\mathrm{AO}$ is not the same as that of $\mathrm{AO}+\mathrm{MI}$, and, despite the activation overlap documented so far, we would predict agency-related differences in the underlying neurocognitive processes.

A third interesting question arises regarding the nature of the interactions and temporal coupling between the observed action and the two proposed simulation processes. According to the single cell recording work on mirror neurons (Rizzolatti and Sinigaglia, 2010), the temporal coupling between the observed action and its internal motor representation is tight (see also Borroni et al., 2005). Indeed, these studies indicate minimal delays between the external event and its motor representation. In contrast, at present we have no information about the possible coupling between the observed action and the MI-related simulation, or about that between both internal simulation processes.

Fourth, it is entirely possible that engaging in MI concurrently with AO draws on resources that are normally used for simulation of the observed action. For example, performance in prediction tasks might be compromised, or perhaps even enhanced, by concurrent $\mathrm{AO}+\mathrm{MI}$ instructions relative to $\mathrm{AO}$ instructions. Competition between these two simulation processes is even more likely in the following two scenarios.

\section{COORDINATIVE AO+MI}

Why should an observer imagine performing action A whilst observing a different action B? When the two actions have nothing in common, this is likely going to be difficult (see section "Conflicting AO+MI"). However, one could well argue that, in overt everyday interactions, performing one action whilst seeing another action done is even more common than imitative behavior. The former is currently studied under the heading of "joint action" (Bekkering et al., 2009), where one actor responds to an observed action with a different, self-performed action, normally in pursuit of a joint or competitive goal (see our example from combat sports in the Introduction). On closer inspection, also congruent actions almost always involve a certain degree of mismatch between observed and imagined action, for example regarding the plane of motion or perspective, or both. A further, prime example of joint action is ensemble music, where the very different actions of, e.g., a jazz singer and bass player are tightly coordinated in time (see Konvalinka et al., 2010). We would then argue that the capability to engage in incongruent $\mathrm{AO}+\mathrm{MI}$, where the two actions merit coordination in one way or another, is grounded in our capacity for joint action. 
Compared to joint action, imagery in $\mathrm{AO}+\mathrm{MI}$ widens the scope of possible scenarios considerably. During both congruent and coordinative $\mathrm{AO}+\mathrm{MI}$, observers normally focus their $\mathrm{MI}$ on selected aspects of the observed action. Indeed, the idea that all degrees of freedom of a complex observed movement could be mapped in a 1:1 fashion onto the observer's motor representation is plain nonsense from the point of view of sensory anatomy alone (Vogt, 2002). Rather, in the motor simulation of an observed action, the case of a purely sensorily driven simulation (rectangle b in Figure 1) is probably quite rare and limited to movements with very few degrees of freedom, such as isolated finger movements. In the majority of cases, however, $\mathrm{AO}$ will be focused on certain aspects of the observed action. Already in congruent $\mathrm{AO}+\mathrm{MI}$, it is clear that $\mathrm{MI}$ allows for a very narrow attentional focus, for example, on the left knee joint of an observed downhill skier and on the observer's corresponding joint. Finally, coordinative $\mathrm{AO}+\mathrm{MI}$ is even more flexible. Returning to our jazz ensemble, the bassist might imagine tapping along with the singer in order to fully capture her intonation and timing. Or in our example from combat sports, the observer might visually focus on the opponent's right arm whilst, in different repeats of the video, focusing on different own body parts and on their optimal imagined response. In short, coordinative $\mathrm{AO}+\mathrm{MI}$ is most likely a common everyday activity, and in formal training settings in sport or motor rehabilitation, it has an abundant range of applications.

\section{CONFLICTING AO+MI}

It is difficult to consider two actions, one observed and one imagined, that cannot be coordinated in some way but are solely conflicting. One example might be a skier observing a movie (showing either himself or someone else) of a slalom but simultaneously imagine himself falling during the same course, but this example might also be classified as a variant of coordinative $\mathrm{AO}+\mathrm{MI}$. In addition, and besides such (interesting) examples, it may be difficult to imagine a case of conflicting $\mathrm{AO}+\mathrm{MI}$ which can be practically beneficial. However, the corepresentation of conflicting instructions, task sets, or motor plans is of course a common research topic in psychology and neuroscience. For instance, most of the available research on automatic imitation effects (Heyes, 2011) relies on the contrast between compatible and incompatible visual stimuli during action planning as a methodological tool. We would thus like to illustrate possibilities for studying conflicting $\mathrm{AO}+\mathrm{MI}$, together with the other two AO+MI states, by means of an experimental paradigm that was recently developed in one of our labs (Eaves et al., 2012).

The starting point for the study by Eaves et al. (2012) was the relatively scarce evidence for automatic imitation effects in movement kinematics, as compared to the ample evidence from studies using reaction times. In each trial, participants were shown the picture of a rhythmical target action (e.g., toothbrushing), followed by a movie of an irrelevant distractor action (e.g., window wiping), followed by rhythmical execution of the target action. Across trials, the distractor action was presented in subtly different tempi, which produced a significant imitation bias during execution. In addition, the imitation bias was significantly stronger for congruent than for incongruent actions (where congruency could be regarding the type of action and/or the plane of motion). We interpreted these results in the context of Cisek and Kalaska's (2010) biased competition framework, where intended and observed actions can be represented as competing sensorimotor streams. For incongruent actions, we proposed that the competition between the two streams was strongly biased toward the intended action, and that, consequently, the coupling between the two streams was relatively weak.

A straightforward means of studying the three $\mathrm{AO}+\mathrm{MI}$ states as proposed here would be to manipulate $\mathrm{MI}$ instructions during $\mathrm{AO}$ in the above paradigm. In a congruent $\mathrm{AO}+\mathrm{MI}$ condition, participants could be asked to imagine performing the instructed action in synchrony with observing a congruent distractor action. Based on the results of the neuroimaging studies reviewed in section "A case for motor imagery during action observation," we would predict an enhanced imitation bias for this condition, relative to pure distractor observation as studied in Eaves et al. (2012). A coordinative AO+MI condition could be implemented by requiring participants to imagine the instructed action in synchrony with a distractor action that is incongruent in terms of action type or plane of motion. Whilst the studies by Hove et al. (2010) and Eaves et al. (2012) indicate stronger synchronization effects for congruent actions, it is also conceivable that explicit instructions to coordinate two different actions, as envisaged here, might produce a similarly strong imitation bias for such coordinative $\mathrm{AO}+\mathrm{MI}$ as for congruent $\mathrm{AO}+\mathrm{MI}$. Finally, conflicting $\mathrm{AO}+\mathrm{MI}$ conditions could be studied by asking participants to imagine holding a static posture of the instructed action during AO. Here we would expect that the imitation bias would be largely abolished. A second means of studying conflicting $\mathrm{AO}+\mathrm{MI}$ would be to display a static image whilst participants imagine rhythmical performance of the instructed action. Such manipulations are suitable for exploring the relative strength of the biasing effects of $\mathrm{AO}$ and MI. Overall, we hope that this example has illustrated that the three $\mathrm{AO}+\mathrm{MI}$ states, as proposed here, can indeed be subjected to detailed experimental investigation.

\section{PERSPECTIVE MATTERS}

As pointed out in Footnote 1, so far we have focused on thirdperson $\mathrm{AO}$ and first-person MI. Whilst a full discussion of all possible scenarios in the related $2 \times 2$ matrix would clearly exceed the scope of the present paper, here we briefly consider possible manipulations of visual perspective for $\mathrm{AO}$ only. In congruent $\mathrm{AO}+\mathrm{MI}$, observers can not only be presented with views of another person (third-person $\mathrm{AO}$ ), but also with first-person displays that show the observer's $\operatorname{limb}(\mathrm{s})$ from a similar viewpoint as during execution. As described in section "A case for motor imagery during action observation,” Macuga and Frey (2012) had manipulated viewpoint during $\mathrm{AO}+\mathrm{MI}$ but these authors only obtained negligible differences-possibly due to the rhythmical task used. Interestingly, the recent clinical trial by Cowles et al. (2013) on AO treatment for stroke patients used a setup which approximated first-person $\mathrm{AO}$, where the patients observed a model actor who was sitting next to them. Observation of a video in first-person perspective, indeed combined with MI, was 
also used as one of the treatment conditions in Ietswaart et al.'s (2011) study. Certainly, differences in visual perspective should not be ignored when trying to account for different outcomes of clinical trials, if only since viewpoint effects have certainly been found in behavioral studies (e.g., Vogt et al., 2003). A possible advantage of third-person visual displays during $\mathrm{AO}+\mathrm{MI}$ is that the observer can keep the two representations related to $\mathrm{AO}$ and MI more easily distinct than two first-person representations. On the other hand, the latter might be more likely to induce a sense of ownership of the observed body parts, as shown in studies on the rubber hand illusion (Haggard and Tsakiris, 2005) and on mirror-box therapy (Altschuler et al., 1999; Kang et al., 2011). Surely more experimental studies and related clinical trials are needed before firm recommendations for presentation in first- or third person perspective, or perhaps for both, can be made.

For coordinative $\mathrm{AO}+\mathrm{MI}$, it appears unnatural to present the observed action in first-person perspective, since this would not match the typical scenario of joint action (see example in the Introduction). We would thus see first-person visual presentations in coordinative $\mathrm{AO}+\mathrm{MI}$ to be of greater interest for experimental studies than for clinical or training applications. The same is possibly true for first-person presentations in conflicting AO+MI. For example, would the interference effects between the first-person MI and the conflicting visual displays as predicted in section "Conflicting $\mathrm{AO}+\mathrm{MI}$ " be stronger for firstor third-person presentation of the distractor movies?

\section{CONCLUDING REMARKS}

The present paper marks the return of one of us (Stefan Vogt) to issues of MI after almost two decades abstaining from the topic, which has developed so healthily in the meantime. It is true that the field of $\mathrm{AO}$ per se, which has grown with at least the same rate over this period, offers ample opportunities to study perception-action relationships, and that MI is not a mandatory step to mediate perception and action (Vogt, 1995, 1996). Furthermore, it is likely to be more attractive for an experimentalist to manipulate visual displays instead of imagery instructions, which are always open to subjective interpretation (Holmes and Calmels, 2008). However, so are visual displays! We hope to have reminded researchers in the fields of $\mathrm{AO}$ and $\mathrm{MI}$ that the two processes do not only share, at least in part, the same neural substrate (although a meta-analysis of the now available evidence from both areas of research is currently lacking), but more importantly, that they are easily carried out simultaneously, most likely not only in the laboratory but also in everyday life. As we have described in section "Multiple roles of motor imagery during action observation," spontaneously performed AO+MI is an important and largely ignored confound in many related behavioral and neuroimaging studies. The act of "putting yourself into another person's shoes," or "action understanding from within" (Rizzolatti and Sinigaglia, 2010) might often involve processes of MI, albeit not necessarily in the sense of a deliberate conscious effort. With this we do not wish to question the possible contribution of motor processes to action understanding and action prediction in general. Rather, we wish to distinguish the latter from a more specific $\mathrm{AO}+\mathrm{MI}$ state where the observer "switches on" his or her own body schema and actively seeks to align this with the observed action,-a process that is difficult to capture without reference to the concept of MI. We have described three subtypes of concurrent AO+MI, namely congruent, coordinative, and conflicting $\mathrm{AO}+\mathrm{MI}$, where particularly the first two bear the potential for a wide range of applications in sports, occupational training as well as neurorehabilitation. $\mathrm{AO}$ and MI are most likely highly intertwined processes, and their joint consideration is fruitful in theoretical and applied contexts alike.

\section{ACKNOWLEDGMENTS}

Some of the ideas in the present paper emerged from discussions with Dan Eaves (Teesside and Lancaster University), who also helped in checking the revised manuscript.

\section{REFERENCES}

Altschuler, E. L., Wisdom, S. B., Stone, L., Foster, C., Galasko, D., Llewellyn, D. M., et al. (1999). Rehabilitation of hemiparesis after stroke with a mirror. Lancet 353, 2035-2036. doi: 10.1016/S0140-6736(99)00920-4

Annett, J. (1996). On knowing how to do things: a theory of motor imagery. Cogn. Brain Res 3, 65-69. doi: 10.1016/0926-6410(95)00030-5

Babiloni, C., Del Percio, C., Rossini, P. M., Marzano, N., Iacoboni, M., Infarinato, F., et al. (2009). Judgment of actions in experts: a high-resolution EEG study in elite athletes. Neuroimage 45, 512-521. doi: 10.1016/j.neuroimage.2008.11.035

Babiloni, C., Marzano, N., Infarinato, F., Iacoboni, M., Rizza, G., Aschieri, P., et al. (2010). "Neural efficiency" of experts' brain during judgment of actions: a highresolution EEG study in elite and amateur karate athletes. Behav. Brain Res. 207, 466-475. doi: 10.1016/j.bbr.2009.10.034

Battaglia, F., Lisanby, S. H., and Freedberg, D. (2011). Corticomotor excitability during observation and imagination of a work of art. Front. Hum. Neurosci. 5:79. doi: 10.3389/fnhum.2011.00079

Bekkering, H., de Bruijn, E. R. A., Cuijpers, R. H., Newman-Norlund, R., van Schie, H. T., and Meulenbroek, R. (2009). Joint action: neurocognitive mechanisms supporting human interaction. Topics Cogn. Sci. 1, 340-352. doi: 10.1111/j.1756-8765.2009.01023.x

Berends, H. I., Wolkorte, R., Ijzerman, M. J., and van Putten, M. J. A. M. (2013). Differential cortical activation during observation and observationand-imagination. Exp. Brain Res. 229, 337-345. doi: 10.1007/s00221013-3571-8

Bianco, G., Feurra, M., Fadiga, L., Rossi, A., and Rossi, S. (2012). Bi-hemispheric effects on corticospinal excitability induced by repeated sessions of imagery versus observation of actions. Restor. Neurol. Neurosci. 30, 481-489. doi: 10.3233/RNN-2012-120241

Borroni, P., Montagna, M., Cerri, G., and Baldissera, F. (2005). Cyclic time course of motor excitability modulation during the observation of a cyclic hand movement. Brain Res. 1065, 115-124. doi: 10.1016/j.brainres.2005.10.034

Brass, M., Bekkering, H., Wohlschläger, A., and Prinz, W. (2000). Compatibility between observed and executed finger movements: comparing symbolic, spatial, and imitative cues. Brain Cogn. 44, 124-143. doi: 10.1006/brcg.2000.1225

Braun, S., Kleynen, M., van Heel, T., Kruithof, N., Wade, D., and Beurskens, A. (2013). The effects of mental practice in neurological rehabilitation; a systematic review and meta-analysis. Front. Hum. Neurosci. 7:390. doi: 10.3389/fnhum.2013.00390

Bubic, A., Von Cramon, D. Y., and Schubotz, R. I. (2010). Prediction, cognition and the brain. Front. Hum. Neurosci. 4:25. doi: 10.3389/fnhum.2010.00025

Buccino, G., Lui, F., Canessa, N., Patteri, H., Lagravinese, G., Benuzzi, et al. (2004). Neural circuits involved in the recognition of actions performed by nonconspecifics: an fMRI study. J. Cogn. Neurosci. 16, 114-126. doi: $10.1162 / 089892904322755601$

Calvo-Merino, B., Glaser, D. E., Grèzes, J., Passingham, R. E., and Haggard, P. (2005). Action observation and acquired motor skills: an fMRI study with expert dancers. Cereb. Cortex 15, 1243-1249. doi: 10.1093/cercor/bhi007

Caspers, S., Zilles, K., Laird, A. R., and Eickhoff, S. B. (2010). ALE meta-analysis of action observation and imitation in the human 
brain. Neuroimage 50, 1148-1167. doi: 10.1016/j.neuroimage.2009. 12.112

Celnik, P., Webster, B., Glasser, D. M., and Cohen, L. G. (2008). Effects of action observation on physical training after stroke. Stroke 39, 1814-1820. doi: 10.1161/STROKEAHA.107.508184

Cisek, P., and Kalaska, J. F. (2010). Neural mechanisms for interacting with a world full of action choices. Annu. Rev. Neurosci. 33, 269-298. doi: 10.1146/annurev.neuro.051508.135409

Clark, S., Tremblay, F., and Ste-Marie, D. (2004). Differential modulation of corticospinal excitability during observation, mental imagery and imitation of hand actions. Neuropsychologia 42, 105-112. doi: 10.1016/S0028-3932(03) 00144-1

Collet, C., Di Rienzo, F., Hoyek, N., and Guillot, A. (2013). Autonomic nervous system correlates in movement observation and imagery. Front. Hum. Neurosci. 7:415. doi: 10.3389/fnhum.2013.00415

Collet, C., Guillot, A., Lebon, F., MacIntyre, T., and Moran, A. (2011). Measuring motor imagery using psychometric, behavioural, and psychophysiological tools. Exerc. Sport Sci. Rev. 39, 85-92. doi: 10.1097/JES.0b013e31820ac5e0

Conson, M., Sarà, M., Pistoia, F., and Trojano, L. (2009). Action observation improves motor imagery: specific interactions between simulative processes. Exp. Brain Res. 199, 71-81. doi: 10.1007/s00221-009-1974-3

Cowles, T., Clark, A., Mares, K., Peryer, G., Stuck, R., and Pomeroy, V. (2013). Observation-to-imitate plus practice could add little to physical therapy benefits within 31 days of stroke: translational randomized controlled trial. Neurorehabil. Neural Repair 27, 173-182. doi: 10.1177/1545968312452470

Crosbie, J. H., McDonough, S. M., Gilmore, D. H., and Wiggam, M. I. (2004). The adjunctive role of mental practice in the rehabilitation of the upper limb after hemiplegic stroke: a pilot study. Clin. Rehabil. 18, 60-68. doi: $10.1191 / 0269215504$ cr702oa

Cross, E. S., Kraemer, D. J. M., Hamilton, A. F., Kelley, W. M., and Grafton, S. T. (2009). Sensitivity of the action observation network to physical and observational learning. Cereb. Cortex 19, 315-326. doi: 10.1093/cercor/bhn083

Decety, J., Jeannerod, M., Germain, M., and Pastene, J. (1991), Vegetative response during imagined movement is proportional to mental effort. Behav. Brain Res. 42, 1-5. doi: 10.1016/S0166-4328(05)80033-6

Decety, J., Jeannerod, M., and Prablanc, C. (1989). The timing of mentally represented actions. Behav. Brain Res. 34, 35-42. doi: 10.1016/S0166-4328(89) 80088-9

Dijkerman, H. C., Ietswaart, M., Johnston, M., and MacWalter, R. S. (2004). Does motor imagery training improve hand function in chronic stroke patients. A pilot study. Clin. Rehabil. 18, 538-549. doi: 10.1191/0269215504cr769oa

Di Pellegrino, G., Fadiga, L., Fogassi, L., Gallese, V., and Rizzolatti, G. (1992). Understanding motor events: a neurophysiological study. Exp. Brain Res. 91, 176-180. doi: 10.1007/BF00230027

Driskell, J. E., Copper, C., and Moran, A. (1994). Does mental practice enhance performance. J. Appl. Psychol. 79, 481-492. doi: 10.1037/0021-9010.79.4.481

Eaves, D. L., Turgeon, M., and Vogt, S. (2012). Automatic imitation in rhythmical actions: kinematic fidelity and the effects of compatibility, delay, and visual monitoring. PLoS ONE 7:e46728. doi: 10.1371/journal.pone.0046728

Edge, D. (1979). Quantitative measures of communication in science: a critical review. Hist. Sci. 17, 102-134.

Ehrsson, H. H., Geyer, S., and Naito, E. (2003). Imagery of voluntary movement of fingers, toes, and tongue activates corresponding body-part-specific motor representations. J. Neurophysiol. 90, 3304-3316. doi: 10.1152/jn.01113.2002

Ertelt, D., Hemmelmann, C., Dettmers, C., Ziegler, A., and Binkofski, F. (2012). Observation and execution of upper-limb movements as a tool for rehabilitation of motor deficits in paretic stroke patients: protocol of a randomized clinical trial. BMC Neurol. 12:42. doi: 10.1186/1471-2377-12-42

Ertelt, D., Small, S., Solodkin, A., Dettmers, C., McNamara, A., Binkofski, F., et al. (2007). Action observation has a positive impact on rehabilitation of motor deficits after stroke. Neuroimage 36, T164-T173. doi: 10.1016/j.neuroimage.2007.03.043

Eskenazi, T., Grosjean, M., Humphreys, G. W., and Knoblich, G. (2009). The role of motor simulation in action perception: a neuropsychological case study. Psychol. Res. 73, 477-485. doi: 10.1007/s00426-009-0231-5

Ewan, L. M., Kinmond, K., and Holmes, P. S. (2010). An observation-based intervention for stroke rehabilitation: experiences of eight individuals affected by stroke. Disabil. Rehabil. 32, 2097-2106. doi: 10.3109/09638288.2010. 481345
Feltz, D. L., and Landers, D. M. (1983). The effects of mental practice on motor skill learning and performance: a meta-analysis. J. Psychol. 5, 25-57.

Feurra, M., Bianco, G., Polizzotto, N. R., Innocenti, I., Rossi, A., and Rossi, S. (2011). Cortico-cortical connectivity between right parietal and bilateral primary motor cortices during imagined and observed actions: a combined TMS/tDCS study. Front. Neural Circuits 5:10. doi: 10.1186/1471-2377-12-42

Filimon, F., Nelson, J. D., Hagler, D. J., and Sereno, M. I. (2007). Human cortical representations for reaching: mirror neurons for execution, observation, and imagery. Neuroimage 37, 1315-1328. doi: 10.1016/j.neuroimage.2007.06.008

Franceschini, M., Agosti, M., Cantagallo, A., Sale, P., Mancuso, M., and Buccino, G. (2010). Mirror neurons: action observation treatment as a tool in stroke rehabilitation. Eur. J. Phys. Rehabil. Med. 46, 517-523.

Frith, C. D. (2010). What is consciousness for? Pragm. Cogn. 18, 497-551. doi: 10.1075/pc.18.3.03fri

Frith, C. D. (2013). The psychology of volition. Exp. Brain Res. 229, 289-299. doi: $10.1007 /$ s00221-013-3407-6

Frith, C. D., and Frith, U. (2006). The neural basis of mentalizing. Neuron 50, 531-534. doi: 10.1016/j.neuron.2006.05.001

Frith, C. D., and Frith, U. (2012). Mechanisms of social cognition. Annu. Rev. Psychol. 63, 287-313. doi: 10.1146/annurev-psych-120710-100449

Gallese, V., Fadiga, L., Fogassi, L., and Rizzolatti, G. (1996). Action recognition in the premotor cortex. Brain 119, 593-609. doi: 10.1093/brain/119.2.593

Gallese, V., Gernsbacher, M. A., Heyes, C., Hickok, G., and Iacoboni, M. (2011). Mirror neuron forum. Persp. Psychol. Sci. 6, 369-407. doi: 10.1177/174569 1611413392

Galton, F. (1883). Inquiries into Human Faculty and its Development. London: MacMillan. doi: 10.1037/14178-000

Garrison, K. A., Winstein, C. J., and Aziz-Zadeh, L. (2010). The mirror neuron system: a neural substrate for methods in stroke rehabilitation. Neurorehabil. Neural Rep. 24, 404-412. doi: 10.1177/1545968309354536

Gatti, R., Tettamanti, A., Gough, P. M., Riboldi, E., Marinoni, L., and Buccino, G. (2013). Action observation versus motor imagery in learning a complex motor task: a short review of literature and a kinematics study. Neurosci. Lett. 540, 37-42. doi: 10.1016/j.neulet.2012.11.039

Gerardin, E., Sirigu, A., Lehericy, S., Poline, J. B., Gaymard, B., Marsault, C., et al. (2000). Partially overlapping neural networks for real and imagined hand movements. Cereb. Cortex 10, 1093-1104. doi: 10.1093/cercor/10.11.1093

Grèzes, J., and Decety, J. (2001). Functional anatomy of execution, mental simulation, observation, and verb generation of actions: a meta-analysis. Hum. Brain Mapp. 12, 1-19. doi: 10.1002/1097-0193(200101)12:1<1::AIDHBM10>3.0.CO;2-V

Grosbras, M. H., Beaton, S., and Eickhoff, S. B. (2012). Brain regions involved in human movement perception: a quantitative voxel-based meta-analysis. Hum. Brain Mapp. 33, 431-454. doi: 10.1002/hbm.21222

Grush, R. (2004). The emulation theory of representation: motor control, imagery, and perception. Behav. Brain Sci. 27, 377-442. doi: $10.1017 /$ S0140525X04000093

Guillot, A., and Collet, C. (2005). Duration of mentally simulated movement: a review. J. Mot. Behav. 37, 10-20. doi: 10.3200/JMBR.37.1.10-20

Guillot, A., Collet, C., Nguyen, V. A., Malouin, F., Richards, C., and Doyon, J. (2009). Brain activity during visual versus kinesthetic imagery: an fMRI study. Hum. Brain Mapp. 30, 2157-2172. doi: 10.1002/hbm.20658

Guillot, A., Di Rienzo, F., Moran, A., MacIntyre, T., and Collet, C. (2012a). Imagining is not doing but involves motor commands: a review of experimental data related to motor inhibition. Front. Hum. Neurosci. 6:247. doi: 10.3389/fnhum.2012.00247

Guillot, A., Hoyek, N., Louis, M., and Collet, C. (2012b). Understanding the timing of motor imagery: Recent findings and future directions. Int. Rev. Sport Exerc. Psychol. 5, 3-22. doi: 10.1080/1750984X.2011.623787

Haggard, P., and Tsakiris, M. (2005). The rubber hand illusion revisited: visuotactile integration and self-attribution. J. Exp. Psychol. Hum. Percept. Perform. 31, 80-91. doi: 10.1037/0096-1523.31.1.80

Hétu, S., Gregoire, M., Saimpont, A., Coll, M. P., Eugene, F., Michon, P. E., et al. (2013). The neural network of motor imagery: an ALE meta-analysis. Neurosci. Biobehav. Rev. 37, 930-949. doi: 10.1016/j.neubiorev.2013.03.017

Hétu, S., Mercier, C., Eugene, F., Michon, P. E., and Jackson, P. L. (2012). Modulation of brain activity during action observation: influence of perspective, transitivity and meaningfulness. PLOS ONE 6:e24728. doi: 10.1371/journal.pone. 0024728 
Heyes, C. (2011). Automatic imitation. Psychol. Bull. 137, 463-483. doi: 10.1037/a0022288

Higuchi, S., Holle, H., Roberts, N., Eickhoff, S. B., and Vogt, S. (2012). Imitation and observational learning of hand actions: prefrontal involvement and connectivity. Neuroimage 59, 1668-1683. doi: 10.1016/j.neuroimage.2011.09.021

Holmes, P., and Calmels, C. (2008). A neuroscientific review of imagery and observation use in sport. J. Mot. Behav. 40, 433-445. doi: 10.3200/JMBR.40.5.433-445

Holmes, P., and Calmels, C. (2011). "Mental practice: neuroscientific support for a new approach," in Performance Psychology: A Practitioner's Guide, eds D. Collins, A. Button, and H. Richards (Oxford: Churchill Livingstone/Elsevier), 231-244.

Hove, M. J., Spivey, M. J., and Krumhansl, C. L. (2010). Compatibility of motion facilitates visuomotor synchronization. J. Exp. Psychol. Hum. Percept. Perform. 36, 1525-1534. doi: 10.1037/a0019059

Ietswaart, M., Johnston, M., Dijkerman, H. C., Joice, S., Scott, C. L., MacWalter, R. S., et al. (2011). Mental practice with motor imagery in stroke recovery: randomized controlled trial of efficacy. Brain 134, 1373-1386. doi: 10.1093/brain/awr077

James, W. (1890). The Principles of Psychology. New York, NY: Holt. doi: 10.1037/11059-000

Jeannerod, M. (1994). The representing brain: neural correlates of motor intention and imagery. Behav. Brain Sci. 17, 187-202. doi: 10.1017/S0140525X00034026

Jeannerod, M. (2001). Neural simulation of action: a unifying mechanism for motor cognition. Neuroimage 14, S103-109. doi: 10.1006/nimg.2001.0832

Jeannerod, M. (2006). Motor Cognition. Oxford: Oxford University Press. doi: 10.1093/acprof:oso/9780198569657.001.0001

Johansson, B. B. (2012). Multisensory stimulation in stroke rehabilitation. Front. Hum. Neurosci. 6:60. doi: 10.3389/fnhum.2012.00060

Kang, Y. J., Ku, J., Kim, H. J., and Park, H. K. (2011). Facilitation of corticospinal excitability according to motor imagery and mirror therapy in healthy subjects and stroke patients. Ann. Rehabil. Med. 35, 747-758. doi: 10.5535/arm.2011.35.6.747

Kelly, A. M. C., and Garavan, H. (2005). Human functional neuroimaging of brain changes associated with practice. Cereb. Cortex 15, 1089-1102. doi: 10.1093/cercor/bhi005

Keysers, C., Kaas, J. H., and Gazzola, V. (2010). Somatosensation in social perception. Nat. Rev. Neurosci. 11, 417-428. doi: 10.1038/nrn2833

Kilner, J. M. (2011). More than one pathway to action understanding. Trends Cogn. Sci. 15, 352-357. doi: 10.1016/j.tics.2011.06.005

Kilner, J. M., Friston, K. J., and Frith, C. D. (2007). Predictive coding: an account of the mirror neuron system. Cogn. Process. 8, 159-166. doi: 10.1007/s10339-0070170-2

Knorr-Cetina, K. D. (1982). Scientific communities or transepistemic arenas of research. A critique of quasi-economic models of science. Soc. Stud. Sci. 12, 101-130. doi: 10.1177/030631282012001005

Konvalinka, I., Vuust, P., Roepstorff, A., and Frith, C. D. (2010). Follow you, follow me: continuous mutual prediction and adaptation in joint tapping. Q. J. Exp. Psychol. 63, 2220-2230. doi: 10.1080/17470218.2010.497843

Kosslyn, S. M. (2010). "Multimodal images in the brain," in The Neurophysiological Foundations of Mental and Motor Imagery, eds A. Guillot and C. Collet (New York, NY: Oxford University Press), 3-16. doi: 10.1093/acprof:oso/9780199546251.003.0001

Lejeune, M., Decker, C., and Sanchez, X. (1994). Mental rehearsal in table tennis performance. Percept. Mot. Skills 79, 627-641. doi: 10.2466/pms.1994.79.1.627

Leonard, G., and Tremblay, F. (2007). Corticomotor facilitation associated with observation, imagery and imitation of hand actions: a comparative study in young and old adults. Exp. Brain Res. 177, 167-175. doi: 10.1007/s00221-0060657-6

Liepert, J., and Neveling, N. (2009). Motor excitability during imagination and observation of foot dorsiflexions. J. Neural Transm. 116, 1613-1619. doi: 10.1007/s00702-009-0287-9

Loporto, M., McAllister, C., Williams, J., Hardwick, R., and Holmes, P. (2011). Investigating central mechanisms underlying the effects of action observation and imagery through transcranial magnetic stimulation. J. Mot. Behav. 43, 361-373. doi: 10.1080/00222895.2011.604655

Lorey, B., Naumann, T., Pilgramm, S., Petermann, C., Bischoff, M., Zentgraf, K., et al. (2013a). How equivalent are the action execution, imagery, and observation of intransitive movements. Revisiting the concept of somatotopy during action simulation. Brain Cogn. 81, 139-150. doi: 10.1016/j.bandc. 2012.09.011
Lorey, B., Naumann, T., Pilgramm, S., Petermann, C., Bischoff, M., Zentgraf, K., et al. (2013b). Neural simulation of actions: effector- versus action-specific motor maps within the human premotor and posterior parietal area. Hum. Brain Mapp. doi: 10.1002/hbm.22246. [Epub ahead of print].

Lotze, M., Montoya, P., Erb, M., Hulsmann, E., Flor, H., Klose, U., et al. (1999). Activation of cortical and cerebellar motor areas during executed and imagined hand movements: an fMRI study. J. Cogn. Neurosci. 11, 491-501. doi: 10.1162/089892999563553

Macuga, K. L., and Frey, S. H. (2012). Neural representations involved in observed, imagined, and imitated actions are dissociable and hierarchically organized. Neuroimage 59, 2798-2807. doi: 10.1016/j.neuroimage. 2011.09.083

Malouin, F., Jackson, P. L., and Richards, C. L. (2013). Towards the integration of mental practice in rehabilitation programs. A critical review. Front. Hum. Neurosci. 7:576. doi: 10.3389/fnhum.2013.00576

McCormick, S. A., Causer, J., and Holmes, P. S. (2012). Eye gaze metrics reflect a shared motor representation for action observation and movement imagery. Brain Cogn. 80, 83-88. doi: 10.1016/j.bandc.2012.04.010

Milner, A. D., and Goodale, M. A. (2008). Two visual systems re-viewed. Neuropsychologia 46, 774-785. doi: 10.1016/j.neuropsychologia.2007.10.005

Moran, A. (2002). In the mind's eye. The Psychologist 15, 414-415.

Moran, A., Guillot, A., Macintyre, T., and Collet, C. (2012). Re-imagining motor imagery: building bridges between cognitive neuroscience and sport psychology. Br. J. Psychol. 103, 224-247. doi: 10.1111/j.2044-8295.2011.02068.x

Morris, T., Spittle, M., and Watt, A. P. (2005). Imagery in Sport. Champaign, IL: Human Kinetics.

Mulder, T. (2007). Motor imagery and action observation: cognitive tools for rehabilitation. J. Neural Transm. 114, 1265-1278. doi: 10.1007/s00702-007-0763-Z

Munzert, J., Lorey, B., and Zentgraf, K. (2009). Cognitive motor processes: the role of motor imagery in the study of motor representations. Brain Res. Rev. 60, 306-326. doi: 10.1016/j.brainresrev.2008.12.024

Nedelko, V., Hassa, T., Hamzei, F., Schoenfeld, M. A., and Dettmers, C. (2012). Action imagery combined with action observation activates more corticomotor regions than action observation alone. J. Neurol Phys. Ther. 36, 182-188. doi: 10.1097/NPT.0b013e318272cad1

Neuper, C., Scherer, R., Wriessnegger, S., and Pfurtscheller, G. (2009). Motor imagery and action observation: modulation of sensorimotor brain rhythms during mental control of a brain-computer interface. Clin. Neurophysiol. 120, 239-247. doi: 10.1016/j.clinph.2008.11.015

Nyberg, L., Eriksson, J., Larsson, A., and Marklund, P. (2006). Learning by doing versus learning by thinking: an fMRI study of motor and mental training. Neuropsychologia 44, 711-717. doi: 10.1016/j.neuropsychologia. 2005.08.006

Oosterhof, N. N., Tipper, S. P., and Downing, P. E. (2012). Visuo-motor imagery of specific manual actions: a multi-variate pattern analysis fMRI study. NeuroImage 63, 262-271. doi: 10.1016/j.neuroimage.2012.06.045

Page, S. J., Levine, P., and Leonard, A. (2007). Mental practice in chronic stroke: results of a randomized, placebo-controlled trial. Stroke 38, 1293-1297. doi: 10.1161/01.STR.0000260205.67348.2b

Pezzulo, G., Candidi, M., Dindo, H., and Barca, L. (2013). Action simulation in the human brain: twelve questions. New Ideas Psychol. 31, 270-290. doi: 10.1016/j.newideapsych.2013.01.004

Porro, C. A., Francescato, M. P., Cettolo, V., Diamond, M. E., Baraldi, P., Zuiani, C., et al. (1996). Primary motor and sensory cortex activation during motor performance and motor imagery: a functional magnetic resonance imaging study. J. Neurosci. 16, 7688-7698.

Press, C., Catmur, C., Cook, R., Widmann, H., Heyes, C., and Bird, G. (2012). fMRI evidence of 'mirror' responses to geometric shapes. PLoS ONE 7:12. doi: 10.1371/journal.pone.0051934

Ramsey, R., Cumming, J., Eastough, D., and Edwards, M. G. (2010). Incongruent imagery interferes with action initiation. Brain Cogn. 74, 249-254. doi: 10.1016/j.bandc.2010.08.005

Rizzolatti, G. (2005). The mirror neuron system and its function in humans. Anat. Embryol. 210, 419-421. doi: 10.1007/s00429-005-0039-z

Rizzolatti, G., and Fabbri-Destro, M. (2010). Mirror neurons: from discovery to autism. Exp. Brain Res. 200, 223-237. doi: 10.1007/s00221-009-2002-3

Rizzolatti, G., Fadiga, L., Fogassi, L., and Gallese, V. (1996). Premotor cortex and the recognition of motor actions. Cogn. Brain Res. 3, 131-141. doi: 10.1016/0926-6410(95)00038-0 
Rizzolatti, G., Fadiga, L., Fogassi, L., and Gallese, V. (2002). "From mirror neurons to imitation: facts and speculations," in The Imitative mind: Development, Evolution, and Brain Bases, eds A. N. Meltzoff and W. Prinz (Cambridge: Cambridge University Press), 247-266. doi: 10.1017/CBO9780511489969.015

Rizzolatti, G., and Sinigaglia, C. (2010). The functional role of the parieto-frontal mirror circuit: interpretations and misinterpretations. Nat. Rev. Neurosci. 11, 264-274. doi: 10.1038/nrn2805

Roure, R., Collet, C., Deschaumes-Molinaro, C., Delhomme, G., Dittmar, A., and Vernet-Maury, E. (1999). Imagery quality estimated by autonomic response is correlated to sporting performance enhancement. Physiol. Behav. 66, 63-72. doi: 10.1016/S0031-9384(99)00026-8

Sakamoto, M., Muraoka, T., Mizuguchi, N., and Kanosue, K. (2009). Combining observation and imagery of an action enhances human corticospinal excitability. Neurosci. Res. 65, 23-27. doi: 10.1016/j.neures.2009.05.003

Solodkin, A., Hlustik, P., Chen, E. E., and Small, S. L. (2004). Fine modulation in network activation during motor execution and motor imagery. Cereb. Cortex 14, 1246-1255. doi: 10.1093/cercor/bhh086

Schubotz, R. I. (2007). Prediction of external events with our motor system: towards a new framework. Trends Cogn. Sci. 11, 211-218. doi: 10.1016/j.tics.2007.02.006

Schuster, C., Hilfiker, R., Amft, O., Scheidhauer, A., Andrews, B., Butler, J. A., et al. (2011). Best practice for motor imagery: a systematic literature review on motor imagery training elements in five different disciplines. BMC Med. 9:75. doi: 10.1186/1741-7015-9-75

Schwoebel, J., Boronat, C. B., and Branch Coslett, H. (2002). The man who executed "imagined" movements: evidence for dissociable components of the body schema. Brain Cogn. 50, 1-16. doi: 10.1016/S0278-2626(02)00005-2

Scott, S. K., McGettigan, C., and Eisner, F. (2009). A little more conversation, a little less action-candidate roles for the motor cortex in speech perception. Nat. Rev. Neurosci. 10, 295-302. doi: 10.1038/nrn2603

Shallice, T. (2004). "The fractionation of supervisory control," in The Cognitive Neurosciences, 3rd Edn., ed M. S. Gazzaniga (Cambridge, MA: MIT Press), 943-956.

Shepard, R. N. (1984). Ecological constraints on internal representation: Resonant kinematics of perceiving, imagining, thinking, and dreaming. Psychol. Rev. 91, 417-447. doi: 10.1037/0033-295X.91.4.417

Springer, A., Parkinson, J., and Prinz, W. (2013). Action simulation: time course and representational mechanisms. Front. Psychol. 4:387. doi: 10.3389/fpsyg.2013.00387

Stürmer, B., Aschersleben, G., and Prinz, W. (2000). Correspondence effects with manual gestures and postures: a study of imitation. J. Exp. Psychol. Hum. Percept. Perform. 26, 1746-1759. doi: 10.1037/0096-1523.26.6.1746

Sully, J. (1892). The Human Mind: a Text-Book of Psychology. London: Longmans Green. doi: 10.1037/12967-000

Titchener, E. B. (1909). Imagery and Sensationalism. New York, NY: MacMillan.

Tremblay, F., Leonard, G., and Tremblay, L. (2008). Corticomotor facilitation associated with observation and imagery of hand actions is impaired in Parkinson's disease. Exp. Brain Res. 185, 249-257. doi: 10.1007/s00221-007-1150-6

Tsukazaki, I., Uehara, K., Morishita, T., Ninomiya, M., and Funase, K. (2012). Effect of observation combined with motor imagery of a skilled hand-motor task on motor cortical excitability: difference between novice and expert. Neurosci. Lett. 518, 96-100. doi: 10.1016/j.neulet.2012.04.061

Van Overwalle, F., and Baetens, K. (2009). Understanding others' actions and goals by mirror and mentalizing systems: a meta-analysis. Neuroimage 48, 564-584. doi: 10.1016/j.neuroimage.2009.06.009

Villiger, M., Estevez, N., Hepp-Reymond, M.-C., Kiper, D., Kollias, S. S., Eng, K., et al. (2013). Enhanced activation of motor execution networks using action observation combined with imagination of lower limb movements. PLOS ONE 8:e72403. doi: 10.1371/journal.pone.0072403

Vogt, S. (1994). Imagery needs preparation, too (Commentary on a target article by M. Jeannerod). Behav. Brain Sci. 17, 226-227. doi: 10.1017/S0140525X00034324
Vogt, S. (1995). On relations between perceiving, imagining and performing in the learning of cyclical movement sequences. Br. J. Psychol. 86, 191-216. doi: 10.1111/j.2044-8295.1995.tb02556.x

Vogt, S. (1996). Imagery and perception-action mediation in imitative actions. Cogn. Brain Res. 3, 79-86. doi: 10.1016/0926-6410(95)00032-1

Vogt, S. (2002). "Visuomotor couplings in object-oriented and imitative actions," in The Imitative Mind: Development, Evolution, and Brain Bases, eds A. N. Meltzoff and W. Prinz (Cambridge: Cambridge University Press), 206-220. doi: 10.1017/CBO9780511489969.012

Vogt, S., Buccino, G., Wohlschläger, A. M., Canessa, N., Shah, N., Zilles, K., et al. (2007). Prefrontal involvement in imitation learning of hand actions: effects of practice and expertise. Neuroimage 37, 1371-1383. doi: 10.1016/j.neuroimage.2007.07.005

Vogt, S., Taylor, P., and Hopkins, B. (2003). Visuomotor priming by pictures of hand postures: perspective matters. Neuropsychologia 41, 941-951. doi: 10.1016/S0028-3932(02)00319-6

Vogt, S., and Thomaschke, R. (2007). From visuo-motor interactions to imitation learning: behavioural and brain imaging studies. J. Sports Sci. 25, 497-517. doi: 10.1080/02640410600946779

Wehner, T., Vogt, S., and Stadler, M. (1984). Task-specific EMG-characteristics during mental training. Psychol. Res. 46, 389-401. doi: 10.1007/BF00309071

Weinberg, R. S. (2008). Does imagery work. Effects on performance and mental skills. J. Im. Res. Sport Phys. Act. 3, 1-21. doi: 10.2202/1932-0191.1025

Williams, J., Pearce, A. J., Loporto, M., Morris, T., and Holmes, P. S. (2012). The relationship between corticospinal excitability during motor imagery and motor imagery ability. Behav. Brain Res. 226, 369-375. doi: 10.1016/j.bbr.2011.09.014

Woolgar, S. W. (1976). "The identification and definition of scientific collectivities," in Perspectives on the Emergence of Scientific Disciplines, eds G. Lemaine, R. MacLeod, M. Mulkay, and P. Weingart (The Hague: Mouton and Co.), 235-245. doi: 10.1515/9783110819038.233

Wuyam, B., Moosavi, S. H., Decety, J., Adams, L., Lansing, R. W., and Guz, A. (1995). Imagination of dynamic exercise produced ventilatory responses which were more apparent in competitive sportsmen. J. Physiol. (Lond.) 482, 713-724.

Zentgraf, K., Munzert, J., Bischoff, M., and Newman-Norlund, R. D. (2011). Simulation during observation of human actions - theories, empirical studies, applications. Vision Res. 51, 827-835. doi: 10.1016/j.visres.2011.01.007

Ziessler, M., Nattkemper, D., and Vogt, S. (2012). The activation of effect codes in response preparation: new evidence from an indirect interference paradigm. Front. Psychol. 3:585. doi: 10.3389/fpsyg.2012.00585

Zuckerman, H. (1987). Citation analysis and the complex problem of intellectual influence. Scientometrics 12, 329-338. doi: 10.1007/BF02016675

Conflict of Interest Statement: The authors declare that the research was conducted in the absence of any commercial or financial relationships that could be construed as a potential conflict of interest.

Received: 13 August 2013; accepted: 06 November 2013; published online: 25 November 2013.

Citation: Vogt S, Di Rienzo F, Collet C, Collins A and Guillot A (2013) Multiple roles of motor imagery during action observation. Front. Hum. Neurosci. 7:807. doi: 10.3389/ fnhum.2013.00807

This article was submitted to the journal Frontiers in Human Neuroscience.

Copyright (c) 2013 Vogt, Di Rienzo, Collet, Collins and Guillot. This is an openaccess article distributed under the terms of the Creative Commons Attribution License (CC BY). The use, distribution or reproduction in other forums is permitted, provided the original author(s) or licensor are credited and that the original publication in this journal is cited, in accordance with accepted academic practice. No use, distribution or reproduction is permitted which does not comply with these terms. 